\title{
Accelerated Thermal Aging Behaviors of EPDM and NBR Vulcanizates
}

\author{
Sung-Seen Choi, ${ }^{*}$ Jong-Chul Kim, and Chang-Su Woo ${ }^{\dagger}$ \\ Department of Chemistry, Sejong University, Seoul 143-747, Korea. "E-mail: sschoi@sejong.ac.kr \\ ${ }^{\dagger}$ Korea Institute of Machinery and Materials, P.O. Box 101, Yuseong, Daejeon 305-600, Korea \\ Received February 11, 2006
}

Key Words : EPDM, NBR, Thermal aging, Activation energy

The crosslink densities of rubber vulcanizates cured by a sulfur accelerator system are changed by thermal aging. ${ }^{1-5}$ Change of the crosslink density occurs by formation of new crosslinks and dissociation of existing crosslinks. ${ }^{3-6}$ Crosslink density change of a rubber vulcanizate with a high sulfur content after thermal aging was larger than that with a low sulfur content. Permanent deformation of a rubber vulcanizate results from the crosslink density change by thermal aging under the deformed state. ${ }^{7}$ Strain applied to a rubber vulcanizate affects the change of crosslink density. The crosslink density of the more strained vulcanizate was changed by thermal aging more than those of the less strained one.,

Ethylene-propylene diene rubber (EPDM) is a weatherresistant rubber and has slow cure characteristics of long induction time and slow cure rate. Acrylonitrile-butadiene rubber (NBR) is oil-resistant rubber and has fast cure characteristics of short induction time and fast cure rate. EPDM and NBR have different chemical properties each other. EPDM is nonpolar and has slow cure characteristics, whereas NBR is polar and has fast cure characteristics. In this work, we studied changes of crosslink densities of EPDM and NBR vulcanizates by thermal aging at high temperatures of $70-100{ }^{\circ} \mathrm{C}$ for long time of 180 days. Levels of the crosslink density change and the activation energies of the vulcanizates were also compared. Thermal aging behaviors depending on the aging time were explained with the activation energy variation.

Figures 1 and 2 show variations of the crosslink density changes of the EPDM and NBR vulcanizates with the aging time, respectively. The crosslink density change was obtained by dividing the difference in the crosslink densities after and before the thermal aging by the crosslink density of the initial sample. The crosslink density change increases as the aging time elapses. Level of the crosslink density change becomes larger by increasing the aging temperature. For the EPDM vulcanizate, the crosslink density change increases notably during the initial period and then the increment becomes smaller. The crosslink densities increase by 10.0 , 17.6 , and $22.6 \%$ after the thermal aging at 70,85 , and $100{ }^{\circ} \mathrm{C}$ for 30 days, respectively, and increase by 17.3, 27.9, and $42.5 \%$ after the thermal aging for 180 days, respectively. The initial 30 day increments ( 0 to 30 days) are 10.0, 17.6, and $22.6 \%$ for 70,85 , and $100{ }^{\circ} \mathrm{C}$, respectively, while the final 30 day increments (150 to 180 days) are $0.2,0.4$, and

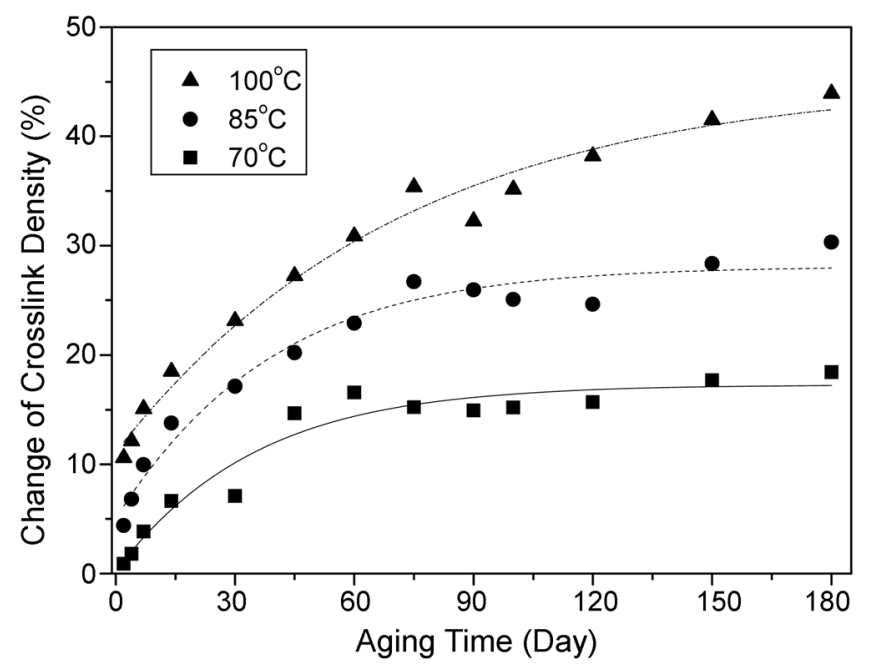

Figure 1. Variation of the crosslink density change of the EPDM vulcanizate by the thermal aging as a function of the aging time. Squares, circles, and triangles indicate the aging temperatures of 70,85 , and $100{ }^{\circ} \mathrm{C}$, respectively.

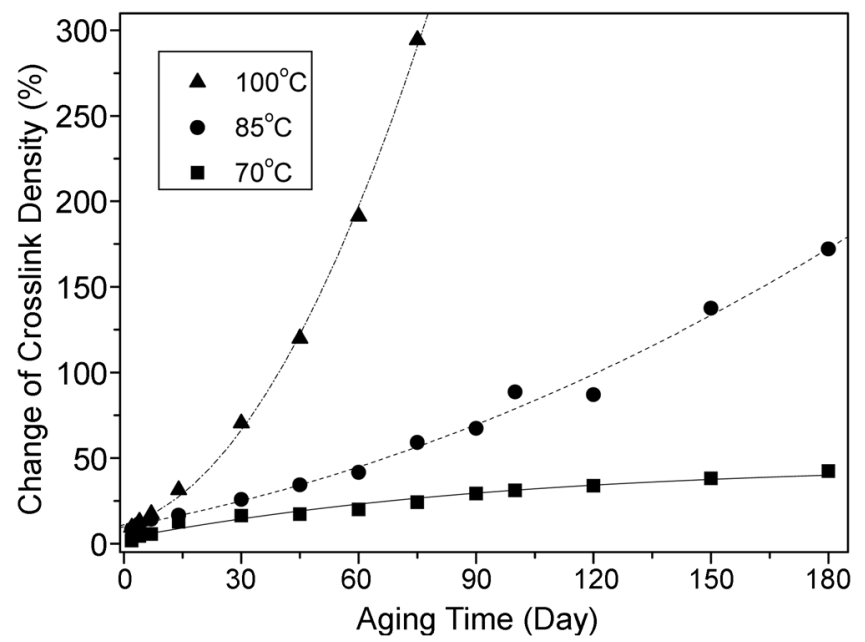

Figure 2. Variation of the crosslink density change of the NBR vulcanizate by the thermal aging as a function of the aging time. Squares, circles, and triangles indicate the aging temperatures of 70,85 , and $100{ }^{\circ} \mathrm{C}$, respectively.

\section{$1.7 \%$, respectively.}

For the NBR vulcanizate, the crosslink density change increases notably with increase of the aging time as shown in Figure 2. Especially, the crosslink density change at 100 


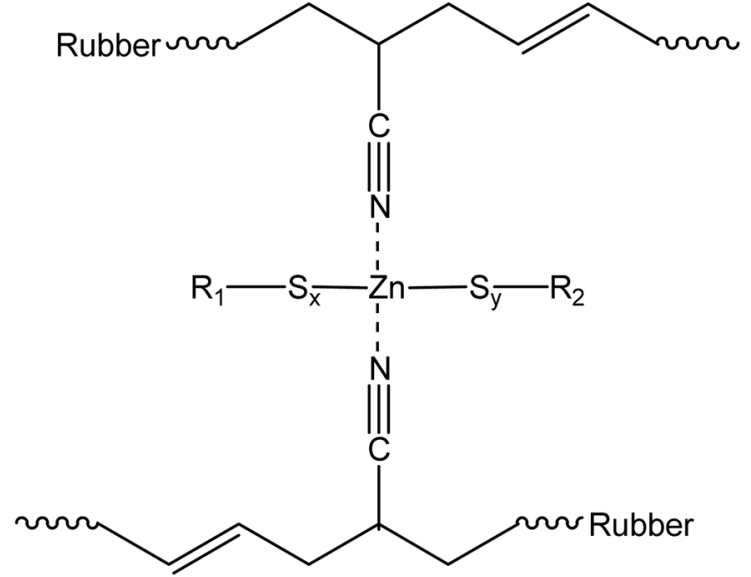

$\mathrm{R}_{1}$ and $\mathrm{R}_{2}=$ accelerator residues

Scheme 1

${ }^{\circ} \mathrm{C}$ increases exponentially as the aging time elapses. The crosslink density increases by about $300 \%$ after the thermal aging at $100{ }^{\circ} \mathrm{C}$ for 75 days. Since the sample was seriously cracked after the thermal aging at $100{ }^{\circ} \mathrm{C}$ for 90 days, the experiments at $100{ }^{\circ} \mathrm{C}$ were carried out only for 75 days. The crosslink densities increase by 16 and $42 \%$ after the thermal aging at $70{ }^{\circ} \mathrm{C}$ for 30 and 180 days, respectively, and increase by 26 and $172 \%$ after the thermal aging at $85^{\circ} \mathrm{C}$ for 30 and 180 days, respectively. The initial 30 day increments ( 0 to 30 days) are 16,26 , and $68 \%$ for 70,85 , and $100{ }^{\circ} \mathrm{C}$, respectively, while the final ones (150 to 180 days) are 5 and $36 \%$ for 70 and $85^{\circ} \mathrm{C}$, respectively.

The crosslink density change of the NBR vulcanizate is much larger than that of the EPDM one. This may be explained with the different chemical properties of EPDM and NBR. NBR is much more polar than EPDM because of the nitrile groups (-CN) of NBR. Nitrile groups of NBR can participate in crosslinking reactions. Fast cure characteristics of NBR are due to the nitrile groups. The nitrile groups do role as ligands in zinc complexes as shown in Scheme 1. Sulfur crosslinks are formed through zinc complexes including zinc ion, accelerator, fatty acid, and sulfur. ${ }^{9,10}$ Zinc complexes in the NBR vulcanizate will be activated by nitrile groups and the crosslinking reactions can be also activated.

We tried to explain the big difference in the thermal aging behaviors of EPDM and NBR vulcanizates in terms of activation energies. Activation energy was obtained from the Arrhenius plot of $\ln k v s 1 / T$, where the $k$ is the crosslink density change and the $T$ is the aging temperature. Figures 3 and 4 give variations of the activation energy with the aging time for the EPDM and NBR vulcanizates, respectively. The activation energies are varied with the aging time. This implies that states of the vulcanizates were varied with the aging time. Density and type of crosslinks are varied hourly because new crosslinks are formed and the existing crosslinks are dissociated by thermal aging. For the EPDM vulcanizate, the activation energy is decreased steeply until

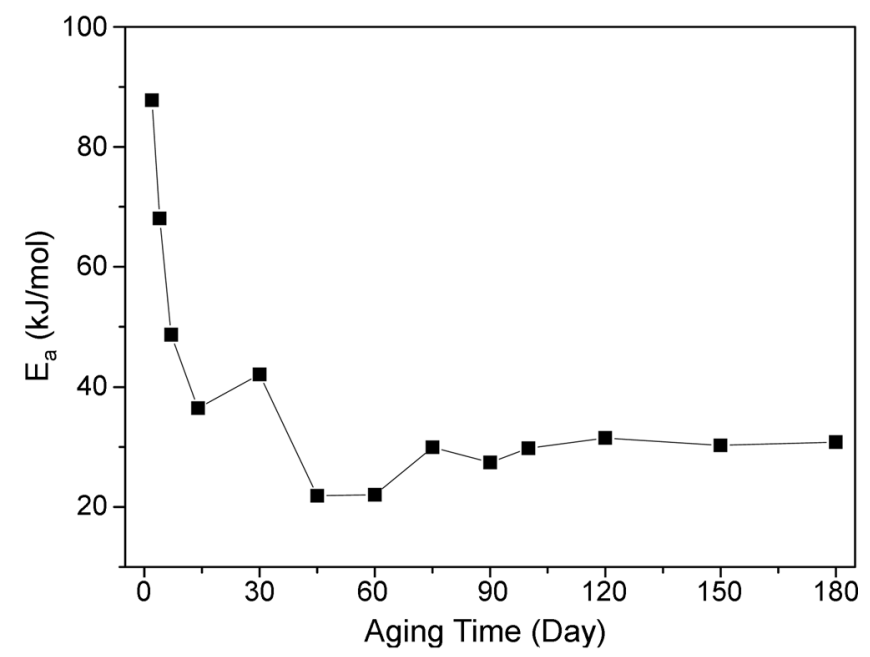

Figure 3. Variation of the activation energy of the EPDM vulcanizate as a function of the aging time.

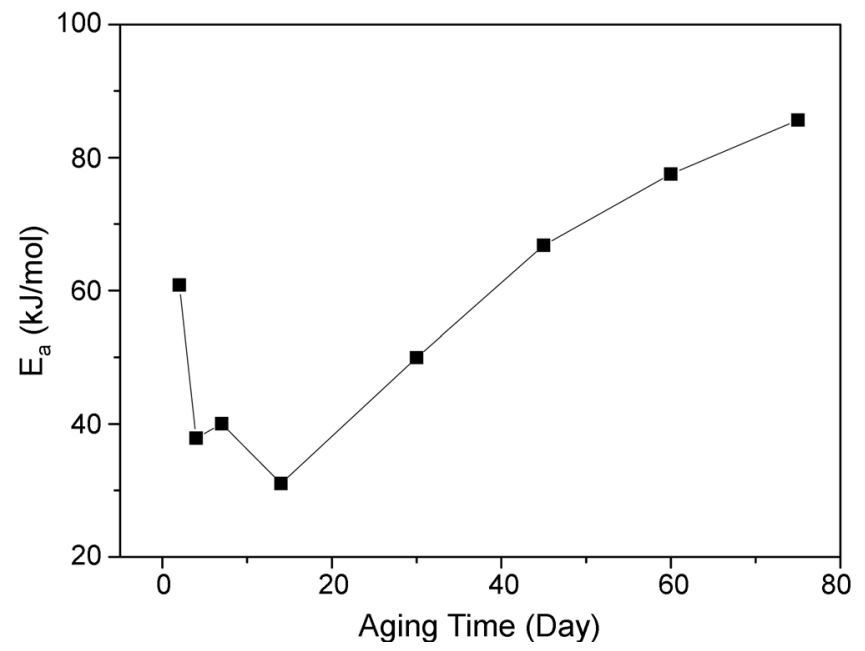

Figure 4. Variation of the activation energy of the NBR vulcanizate as a function of the aging time.

45 days and then keep the values of a narrow range as shown in Figure 3. This can be explained with the reactivity of EPDM and migration and gathering of the crosslinkingrelated chemicals such as zinc complexes, curative residues, sulfur, and so on. In general, sulfur crosslinks are made between allylic carbons. ${ }^{9}$ Since the EPDM does not have lots of allylic carbons, it is not easy to make sulfur crosslinks in EPDM by thermal aging. As the time elapses, the crosslinking-related chemicals will gather around the $\mathrm{C}=\mathrm{C}$ double bonds. The gathered chemicals react with rubber chains to make new crosslinks.

The NBR vulcanizate shows the very different trends to the EPDM one. The activation energy decreases steeply and then increases notably as shown in Figure 4. Formation of new crosslinks in NBR is more favorable than that in EPDM because NBR is much more polar than EPDM as discussed previously. For the NBR vulcanizate, crosslinking reactions occur very fast when the crosslinking-related chemicals gather around the $\mathrm{C}=\mathrm{C}$ double bonds and nitrile groups. The 
remained crosslinking-related chemicals will be consumed very fast by crosslinking reactions involving the nitrile groups of NBR and then the activation energy will be increased as the aging time elapses. The experimental results say that the crosslink density changes are varied with the compositions of rubber vulcanizates and characteristics of thermal aging behaviors of a rubber vulcanizate are described well using the activation energy change with the aging time.

\section{Experimental Section}

EPDM and NBR vulcanizates were composed of rubber (EPDM or NBR), filler (carbon black and calcium carbonate), curatives (fatty acids, zinc oxide, accelerators, and sulfur), antidegradants, and processing aids. KEP-980 of Kumho Petroleum Co. (ethylene content $70.5 \mathrm{wt} \%$, propylene content $25.0 \mathrm{wt} \%$, and ENB content $4.5 \mathrm{wt} \%$ ) was employed as EPDM and KNB35LH of Kumho Petroleum Co. (acrylonitrile content $34 \mathrm{wt} \%$ ) was employed as NBR. Total sulfur contents of the EPDM and NBR vulcanizates were 1.13 and $1.06 \mathrm{wt} \%$, respectively.

Sample dimension was $100 \times 25 \mathrm{~mm}$ with $2 \mathrm{~mm}$ thickness. The thermal aging experiments were carried out at constant temperatures of 70,85 , and $100{ }^{\circ} \mathrm{C}$ in a convection oven. The aging times were $2,4,7,14,30,45,60,75,90$, $100,120,150$, and 180 days. Crosslink densities of the samples before and after the thermal aging were measured by swelling method. Organic additives in the samples were removed by extracting with THF and $n$-hexane for each 2 days and they were dried for 2 days at room temperature.
The weights of the organic materials-extracted samples were measured. They were soaked in $n$-decane for 2 days and the weights of the swollen samples were measured. The swelling ratio $(\mathbf{Q})$ was calculated by the equation of $\mathbf{Q}=\left(\mathbf{W}_{\mathbf{s}}-\right.$ $\left.\mathbf{W}_{\mathbf{u}}\right) / \mathbf{W}_{\mathbf{u}}$, where $\mathbf{W}_{\mathbf{s}}$ and $\mathbf{W}_{\mathbf{u}}$ are weights of the swollen and unswollen samples. The reciprocal swelling value, $\mathbf{1 / Q}$, was used as the apparent crosslink density. ${ }^{11}$ Experiments were carried out three times and they were averaged.

Acknowledgements. This research has been supported by Reliability Design Technology Program (grant no. M10401000005) of Ministry of Science and Technology, Korea.

\section{References and Notes}

1. Blackman, E. J.; McCall, E. B. Rubber Chem. Technol. 1970, 43, 651

2. Parks, C. R.; Brown, R. J. Rubber Chem. Technol. 1976, 49, 233.

3. Choi, S.-S. Kor. Polym. J. 1999, 7, 108

4. Choi, S.-S.; Han, D.-H.; Ko, S.-W.; Lee, H. S. Bull. Kor. Chem. Soc. 2005, 26, 1853

5. Choi, S.-S.; Ha, S.-H.; Woo, C.-S. Bull. Kor. Chem. Soc. 2006, 27, 429.

6. Gradwell, M. H. S.; McGill, W. J. J. Appl. Polym. Sci. 1996, 61, 1515.

7. Choi, S.-S. Bull. Kor. Chem. Soc. 2000, 21, 628

8. Choi, S.-S. Polym. Int. 2001, 50, 107.

9. Layer, R. W. Rubber Chem. Technol. 1992, 65, 211.

10. McCleverty, J. A.; Morrison, N. J.; Spencer, N.; Ashworth, C. C.; Bailey, N. A.; Johnson, M. R.; Smith, J. M. A.; Tabbiner, B. A.; Taylor, C. R. J. Chem. Soc. Dalton Trans. 1980, 1945.

11. Parks, C. R.; Brown, R. J. Rubber Chem. Technol. 1976, 49, 233. 